\title{
A multi-objective reliable programming model for disruption in supply chain
}

\author{
Ebrahim Teimuory ${ }^{a}$, Fateme Bozorgi Atoei ${ }^{a^{*}}$, Emran Mohammadi $^{\mathrm{a}}$, Ali Bozorgi Amiri
}

${ }^{a}$ Department of Industrial Engineering, Science \& Technology University, Tehran, Iran ${ }^{b}$ Department of Industrial Engineering, Tehran University, Tehran, Iran

\section{H R O N I C L E}

Article history:

Received October 18, 2012

Received in revised format

28 January 2013

Accepted 30 March 2013

Available online

March 312013

Keywords:

Disruption risk

Reliability

Supply chain

Risk management

Multi-objective

\section{A B S T R A C T}

One of the primary concerns on supply chain management is to handle risk components, properly. There are various reasons for having risk in supply chain such as natural disasters, unexpected incidents, etc. When a series of facilities are built and deployed, one or a number of them could probably fail at any time due to bad weather conditions, labor strikes, economic crises, sabotage or terrorist attacks and changes in ownership of the system. The objective of risk management is to reduce the effects of different domains to an acceptable level. To overcome the risk, we propose a reliable capacitated supply chain network design (RSCND) model by considering random disruptions risk in both distribution centers and suppliers. The proposed study of this paper considers three objective functions and the implementation is verified using some instance.

(C) 2013 Growing Science Ltd. All rights reserved.

\section{Introduction}

During the past decade, there has been growing interests on supply chain risk and supply chain disruptions, which happens due to natural disasters such as floods, earthquakes, etc. or intentional or unpremeditated human actions such as industrial accidents, terrorist strikes, etc. Risk management is a structured approach for managing uncertain events through a sequence of human activities, which includes different activities, which consist of risk assessment, strategy development and decrease on unnecessary resources. In fact, the primary objective of risk management is to reduce the strokes of different risks in a predefined level using appropriate decisions. Risks may refer to numerous types of menaces caused by humans, environment, technology, politics and organizations. Some risk management strategies concentrate on tackling risks associated with distributions in the network, which might be caused by natural disasters or planned operations such as earthquakes, terrorist attacks, etc.

Supply chain risk management attempts to reduce supply chain's vulnerability by identifying and analyzing the risk of failure points within the supply chain. There are different strategies for risk Corresponding author. Tel: +989113546910

E-mail: bozorgi.atoei@yahoo.com (F. Bozorgi Atoei)

(C) 2013 Growing Science Ltd. All rights reserved. doi: $10.5267 / \mathrm{j} . \mathrm{ms} 1.2013 .03 .028$ 
management. According to Snyder (2010) there are, at least, five strategies to reduce disruptions. The first one is associated with keeping extra inventory to safeguard against possible future disruptions. The second one is associated with routine sourcing, where, firms regularly source raw materials from more than one supplier. In this strategy, if one supplier is disrupted, the firm is not faced with any shortage in raw materials since the other supplier(s) may still be operational. The third strategy is called contingent rerouting where similar to routine sourcing where it assumes the firm has multiple suppliers and when one supplier is disrupted, the firm switches into non-disrupted suppliers to prevent from any disruption. However, there must be sufficient flexibility for having such change. Demand substitution is another strategy where one product is out of stock due to a disruption and the firm may try to change demand to another available product. Financial mitigation is another strategy where firms may purchase insurance policies to protect themselves against any possible disruptions. Finally, acceptance is the last strategy where the cost of mitigation strategies outweighs the potential advantages and the firm may simply choose to accept the risk of disruptions.

Zegordi (2012) states all of the reduce strategies can be categorized into two main types, preventive and recovery, where preventive solutions can be categorized as robustness, resiliency, security-based and agility strategies. Probability of risks could be reduced with an increase in the reliability of the whole system. For this reason, the reliability in network design of the supply chain has been proposed and, in the recent years, there has been special care for creating reliable systems. According to Snyder (2003), a system is called reliable if, "in the occurrence of failure of a part or parts of the system, it is able to perform its duties, effectively". Since the objective of this paper is to minimize the cost of extension, transport and facility placement costs, appropriate and efficient mathematical models are considered to increase the system's reliability, simultaneously. Modeling of this class of problems by considering probability disruptions in the system must be considered in systems' performance under all possible conditions, both normal and disrupted event (Cui, 2010) and in this paper we concentrate on reliable locating of facilities. In addition, in most of these studies, the "reliability issue" is to accomplish on the classic of P-Median Problem and Uncapacitated Fixed charge Location Problem; for the brevity from now on, they are called UFLP and PMP and reliable locating issues associated with them are called RPMP and RUFLP, respectively.

Drezner (1987) examined the facility location under random disruption risks and presented two models where in first one, a reliable PMP was examined, which considers a given probability for the failure of facilities and the objective was to minimize the expected demand-weighted travel distance. The second model called the (p,q)-center problem considers $p$ facilities, which must be located by considering a minimax objective cost function where at most $q$ facilities may fail. In both problems, customers are chosen from the nearest non-disrupted facility based on a neighborhood search heuristic approach in both problems. Lee (2001) proposed an efficient method based on space filling curves to solve the RPMP, which is a continuous locating model and the probability of facilities' failure cannot be independent.

Snyder (2003) investigated the issues of RUFLP and RPMP based on the expected failure and maximum failure expenditures. Here, locating facilities were taken into account so that the total system's cost would be minimized under the normal operating conditions. Depending on whether a facility fails, the system's cost after reallocation of customers cannot exceed a predetermined limit of $\left(\mathrm{V}^{*}\right)$. Snyder and Daskin(2006), in another work, implemented the scenario planning technique to reformulate their previous problem and introduced the concept of stochastic p-robustness where the relative regret was always less than $p$ for any possible scenario. One obvious problem happens when the size of the problem increases since the scenario technique considers all disruption scenarios and complexity of the resulted problem creates trouble. Berman et al. (2007) presented a PMP, in which the objective function was to minimize the demand-weighted transportation cost components. They considered site dependent disruption probabilities associated with various DCs. Qi et al. (2010) investigated the SCND under random disruptions with inventory control decisions by assuming that 
when a retailer is disrupted, any inventory on hand at the retailer is unusable and the resulted customers' unmet demands assigned to a retailer are backlogged under a predefined penalty. The resulted model was a concave minimization problem and the Lagrangian relaxation algorithm was implemented as a solution strategy. Li and Ouyang (2010) investigated the SCND under random disruption risks, in which the disruption probabilities were considered as site-dependent and correlated, geographically. Lim et al. (2010) proposed the SCND under random disruptions by reinforcing selected DCs where disruption probabilities were also site-dependent. They categorized DCs into two groups of unreliable and reliable and incorporated the reliable backup DCs assumption to formulate their proposed model. Peng et al. (2011) developed a capacitated version of SCND under random disruptions with stochastic p-robustness criteria and site dependent disruption probabilities using a method originally developed by Snyder and Daskin (2006).

\section{The proposed study}

The proposed model of this paper considers a three level supply chain including customers, distributors and suppliers where the goal is to minimize costs and maximize reliability. In this model, there are potential locations for distributors and these potential locations have different reliabilities. Once a disruption occurs in a distribution center, the center loses part of its capacity, it does not fail completely and is able to answer part of the customer's needs and the rest of the disrupted DC's demand can be supplied by other DCs. Under normal condition with no disruption, it is possible that some DCs are deficient (support). To express various states of the disruption, different scenarios are considered. Disruptions occurrence in suppliers and distribution centers happen, which follow normal distributions with discrete scenarios. These disruptions in each scenario could be different incidents. For example, in the first scenario, it is possible for distributors 1 and 3 and supplier 2 to be disrupted; this disruption could be an earthquake for the first distributor, a flood for the second distributor and a labor strike for the second supplier.

\subsection{Assumptions}

- Demand is uncertain and has normal distribution.

- Demands of customers are independent from each other and, as a result, the covariances among retailers with each distributors are zero.

- Current policy is (r, Q).

- The model is considered for one production.

- The model is considered for a limited period of time.

- The customer does not keep inventory so there is no need to control the inventory for the customer.

- Customer has no capacity constraints.

- If customer's demand is not fulfilled, there will be a shortage.

- A certain number of places have been considered for setting up distribution centers, in which the decision on opening or closing the facilities would be performed.

- Unreliability only would be considered in the occurrence of disruption and other factors ignored.

- Probability of disruption is different and independent for various facilities' locations and suppliers.

- Suppliers and customers have their own specific places and the DC is just required to be located (discrete locating).

- Distribution centers and suppliers have limited capacities.

\subsection{Innovation}

- Random disruptions in the location, capacity of distribution centers, the location and capacity of suppliers have been considered. 
- Due to a disruption, distribution centers would not lose all their capacities and only a fraction of their capacities would be impaired.

- Either in disruption or normal condition, in case of shortage, the distribution centers can carry goods to each other (support cover).

- Capacity percentage of distribution centers are influenced by disruption and follows a normal distribution.

- Every customer can be assigned to multiple distribution centers according to the distance and costs to supply its needs.

- Reliability is considered as range.

- Demand is uncertain and follows the normal distribution.

- The proposed model also considers different scenarios. It uses a scenario for entering the possibility of disruption and modeling the problem.

- This model uses the chance constraint for entering the random variable.

- Considering the cost variance

This paper determines location for distribution centers and allocates customers to distribution centers. The problem formulation also determines the amount of product sent to customers from distribution centers, as well as the amount delivered from suppliers to distribution centers. Finally, we determine how to allocate the distribution centers to the suppliers and also we determine the amount of products received from any of the suppliers by distribution center.

Index:

$I=$ Suppliers $\quad i=1,2 \ldots n$

$\mathrm{J}=$ Set of potential distribution centers $\quad \mathrm{j}=1,2 \ldots \mathrm{n}$

$j^{\prime}=$ Set of distribution centers that are disrupted or deficient $j^{\prime} \in J$

$\mathrm{K}=$ Set of customers

$\mathrm{k}=1,2 \ldots \mathrm{k}$

$\mathrm{S}=$ Set of scenarios

$\mathrm{s}=1,2 \ldots \mathrm{s}$

Parameters:

$D_{\mathrm{k}}$ Demand of the $k^{\text {th }}$ customer which is a normal random variable $\left(\mu_{j}, \sigma_{j}^{2}\right)$,

$f_{j} \quad$ Fixed costs for opening and operating $\mathrm{DC}_{\mathrm{j}}$,

$P \quad$ The total number of distribution centers which should be localized,

$g_{i j} \quad$ Fixed cost per shipment from supplier $i$ to distribution center $j$,

$k_{i j}$ Transportation fixed cost of each supplier $i$ to $D C_{j}$,

$C_{j j} \quad$ Transportation unit cost from each normal $D C_{j}$ to each deficient $D C_{j}\left(D C_{j}\right)$,

$d_{j k}$ Transportation cost from $D C_{j}$ to $k$ customer,

$S_{j} \quad$ Fixed cost per order from $D C_{j}$,

$h_{j} \quad$ The annual maintenance cost per unit in $D C_{j}$,

$I_{j s}$ Inventory in $D C_{j}$ under the scenario $s$,

$q_{s} \quad$ Disruption probability in scenario $s$,

$\operatorname{cap}_{j}$ Capacity of $D C_{j}$,

The percentage of the total capacity in $D C_{j}$ that is affected by disruption when it is opened,

$a_{j s} \quad$ under the scenario $\mathrm{s}$

$\pi_{j} \quad$ The penalty cost of shortage in $D C_{j}$ per unit of demand,

$b_{j s}$ The amount of shortage in $D C_{j}$ under scenario $s$,

$r_{j s} \quad$ Reliability for the place of $j$ under scenario $s,\left(0 \leq r_{j s} \leq 1\right)$,

$\operatorname{cap}_{i}$ Supplier capacity. 
$a_{i s}$ The percent of capacity of supplier i under scenario s that is affected by disruption.

\section{Decision Variables}

- Continuous variables

$\mathrm{y}_{j k} \quad$ Percentage of product that customer $k$ can allocate to $D C_{j}, \quad 0 \leq y_{j k} \leq 1$,

$T_{j j s}$ The amount of goods shipped from normal distribution Center $\left(D C_{j}\right)$ to deficient distribution center $\left(D C_{j}\right)$ in scenario $s$,

$D_{j} \quad$ The total annual demand which will be allocated to $D C_{j}$,

$n_{j}$ The number of orders in $D C_{j}$,

$Y_{i j} \quad$ Percentage of $D C_{j}$ 's demand which will be sent to supplier $i, \quad 0 \leq Y_{i j} \leq 1$

$Z_{i j} \quad$ The amount of goods that supplier $i$ will send to $D C_{j}$,

$\mathrm{V}_{\mathrm{j} j \mathrm{~s}} \quad$ The amount of goods that $D C_{j}$ will send to $\left(D C_{j}\right)$ under scenario $s$ due to disruption or deficiency.

Zero - One variable

$$
X_{j}=\left\{\begin{array}{rr}
1 & \text { if } D C_{\mathrm{j}} \text { is open } \\
0 & \text { otherwise }
\end{array}\right.
$$

Cost

Fixed cost of locating $=f_{j} x_{j}$

\section{Running Inventory Costs}

The cost of ordering $=s_{j} n_{j}$

Shipping costs from suppliers to DCs $=\sum_{i}\left(g_{i j}+k_{i j} Z_{i j}\right) n_{j}$

Maintenance cost $=\sum_{s} q_{s} I_{j s} h$

Disruption costs $=\sum_{s} q_{s}\left(\sum_{j \in J_{s}}\left(\sum_{j} T_{j j s} C_{j j} X_{j}\right)\right)$

Shipping cost from located DCs to the customers $=d_{j k} \mu_{k} y_{j k}$

Shortage costs $=b_{j s} \pi_{j} \sum_{s} q_{s}$

Regarding the expected total cost, the first objective function will be as follow: (Bozorgi Atoei et al., 2012)

$$
\begin{aligned}
\min \left[\sum_{j} f_{j} x_{j}+\right. & \left(\sum_{j}\left(s_{j} n_{j}+\sum_{i}\left(g_{i j} n_{j}+k_{i j} Z_{i j}\right)+\sum_{s} q_{s}\left(I_{j s}\right) h_{j}\right)+\sum_{s} q_{s}\left(\sum_{j \in J_{s}}\left(\sum_{j} T_{j j s} C_{j j} X_{j}\right)\right)\right)+\sum_{j} \sum_{k} d_{j k} \mu_{k} y_{j k} \\
& \left.+\sum_{j} \sum_{s} q_{s} b_{j s} \pi_{j}\right]
\end{aligned}
$$

We believe the expected total cost is not enough for making appropriate decisions. When we concentrated only the expected total cost the design scheme may be suboptimal if the total cost considerably change but to randomness, for this reason, the variance of total cost provides a good condition for decision makers to make decision according to their preference (Gharegozloo et al., 2012; Azeron et al., 2008). To handle this problem, we use an absolute deviation as Yu and Li (2000) proposed, which is as follows: 
$\sigma(o)=\sum_{s \in S} p_{s} v_{s}+\lambda \sum_{s \in S} p_{s}\left|v_{s}-\sum_{s^{\prime} \in S} p_{s^{\prime}} v_{s^{\prime}}\right|$,

where $\lambda$ is the weight of the less sensitive-solution to data changing in all scenarios. For minimizing the Eq. (2), Yu and Li (2000) presented an effective method, which is modeled as follows:

$\min \sum_{s \in S} p_{s} v_{s}+\lambda \sum_{s \in S} p_{s}\left[v_{s}-\sum_{s^{\prime} \in S} p_{s^{\prime}} v_{s^{\prime}}+2 \theta_{s}\right]$

subject to:

$\begin{array}{ll}v_{s}-\sum_{s \in S} p_{s} v_{s}+\theta_{s} \geq 0 & \forall \mathrm{s} \in \mathrm{S} \\ \theta_{S} \geq 0 & \forall \mathrm{s} \in \mathrm{S}\end{array}$

If $v_{\mathrm{s}}$ is bigger than $\sum p_{\mathrm{s}} v_{\mathrm{s}}, \theta_{\mathrm{s}}$ is equal to 0 , otherwise $\theta_{\mathrm{s}}=\sum \mathrm{p}_{\mathrm{s}} \mathrm{v}_{\mathrm{s}}-v_{\mathrm{s}}$. In this here, we use Yu and Li's method but as the expected value of costs and their variance are against, we write a two-objective model, which separates the two presented terms in Eq. (3). The variance of cost as follow:

$$
\begin{aligned}
& \min \sum_{s} q_{s}\left[\sum_{\mathrm{j}} \mathrm{I}_{\mathrm{js}} \mathrm{h}_{\mathrm{j}}+\sum_{\mathrm{j} \in \mathrm{j}_{s}}\left(\sum_{\mathrm{j}} \mathrm{T}_{\mathrm{j} j \mathrm{~s}} \mathrm{C}_{\mathrm{jj}} \mathrm{X}_{\mathrm{j}}\right)+\sum_{\mathrm{j}} \mathrm{b}_{\mathrm{js}} \mathrm{r}_{\mathrm{j}}\right] \\
& +\partial \sum_{s \in S} q_{s}\left\lceil\left(\sum_{j} \mathrm{I}_{j} \mathrm{~h}_{\mathrm{j}}+\sum_{\mathrm{j} \in \mathrm{j}_{\mathrm{s}}}\left(\sum_{\mathrm{j}} \mathrm{T}_{\mathrm{j} j \mathrm{~s}} \mathrm{C}_{\mathrm{jj}} \mathrm{X}_{\mathrm{j}}\right)+\sum_{\mathrm{j}} \mathrm{b}_{\mathrm{js}} \pi_{\mathrm{j}}\right)\right. \\
& \left.-\sum_{s \in S} q_{\dot{s}}\left(\sum_{\mathrm{j}} \mathrm{I}_{\mathrm{j}} \mathrm{h}_{\mathrm{j}}+\sum_{\mathrm{j} \in \mathrm{j}_{\hat{s}}}\left(\sum_{\mathrm{j}} \mathrm{T}_{\mathrm{j} j \dot{s}} \mathrm{C}_{\mathrm{jj}} \mathrm{X}_{\mathrm{j}}\right)+\sum_{\mathrm{j}} \mathrm{b}_{\mathrm{j} \dot{s}} \mathrm{\pi}_{\mathrm{j}}\right)+2 \theta_{s}\right]
\end{aligned}
$$

Third objective functions maximize the reliability (Bozorgi Atoei et al., 2012)

$\max \sum_{j} \sum_{s} r_{j s} X_{j}$

Finally, the model will be as follows:

$$
\begin{aligned}
\min Z_{1}=\left[\sum_{j} f_{j} \mathrm{x}_{j}\right. & +\left(\sum_{j}\left(s_{j} n_{j}+\sum_{i}\left(g_{i j} n_{j}+k_{i j} Z_{i j}\right)+\sum_{s} q_{s}\left(I_{j}\right) h_{j}\right)+\sum_{s} q_{s}\left(\sum_{j \in J_{s}}\left(\sum_{j} T_{j j s} C_{j j} X_{j}\right)\right)\right) \\
& \left.+\sum_{j} \sum_{k} d_{j k} \mu_{k} y_{j k}+\sum_{j} \sum_{s} q_{s} b_{j s} \pi_{j}\right]
\end{aligned}
$$

$\min Z_{2}=\sum_{s} q_{s}\left[\sum_{j} I_{j} h_{j}+\sum_{j \in j_{s}}\left(\sum_{j} T_{j j s} C_{j j} X_{j}\right)+\sum_{j} b_{j s} \pi_{j}\right]+\partial \sum_{s \in S} q_{s}\left[\left(\sum_{j} I_{j} h_{j}+\sum_{j \in j_{s}}\left(\sum_{j} T_{j j s} C_{j j} X_{j}\right)+\right.\right.$ $\left.\left.\sum_{j} b_{j s} \pi_{j}\right)-\sum_{s \in S} q_{\dot{s}}\left(\sum_{j} I_{j} h_{j}+\sum_{j \in j_{j}}\left(\sum_{j} T_{j j j} C_{j j} X_{j}\right)+\sum_{j} b_{j \dot{s}} \pi_{j}\right)+2 \theta_{s}\right]$

$\max Z_{3}=\sum_{j} \sum_{s} r_{j s} X_{j}$

Subject to:

$\sum_{j} X_{j}=\mathrm{p}$

$\sum_{j} y_{j k}=1$

$\forall k \in K$

$y_{j k} \leq X_{j}$
$\sum_{k} D_{k} y_{j k} \leq\left(1-a_{j s}\right) \operatorname{cap}_{j} X_{j}$

$\forall k \in K, j \in J$ 


$$
\begin{aligned}
& n_{j}=\sqrt{\frac{D_{j} h_{j}}{2 S_{j}}} \\
& \forall j \in J \\
& D_{j} \geq \sum_{k} D_{k} y_{j k} \\
& \forall j \in J \\
& \sum_{j} D_{j} Y_{i j} \leq\left(1-a_{i s}\right) \operatorname{cap}_{i} \quad \forall s, i \\
& Z_{i j}=D_{j} Y_{i j} \quad \forall j, i \\
& \sum_{i} Z_{i j}+\sum_{j \neq j} T_{j j s} X_{j}-D_{j}-\sum_{j \neq j} T_{j j s} X_{j}=I_{j s}-b_{j s} \quad \forall s, j \\
& \sum_{j} T_{j j s}<=\sum_{i} Z_{i j} \quad \forall s, j, J \neq j \\
& \sum_{i} y_{i j}<=1 \\
& \forall j \in J \\
& Y_{i j} \leq X_{j} \\
& Z_{i j} \leq M * X_{j} \\
& {\left[\sum_{j} I_{j} h_{j}+\sum_{j \in j_{s}}\left(\sum_{j} T_{j j s} S_{j j} X_{j}\right)+\sum_{j} b_{j s} \pi_{j}\right]} \\
& -\sum_{s} q_{s}\left[\sum_{j} \mathrm{I}_{j \mathrm{~s}} \mathrm{~h}_{\mathrm{j}}+\sum_{\mathrm{j} \in \mathrm{j}_{s}}\left(\sum_{\mathrm{j}} \mathrm{T}_{\mathrm{j} j \mathrm{j}} \mathrm{C}_{\mathrm{jij}} \mathrm{X}_{\mathrm{j}}\right)+\sum_{j} \mathrm{~b}_{\mathrm{j} s} \mathrm{~T}_{\mathrm{j}}\right]+\theta_{s} \geq 0 \\
& r_{j s}<=1-a_{j s} \\
& \forall i, j \\
& \forall j \in J \\
& \forall s \in S
\end{aligned}
$$

Eq. (8) is the first objective function and states the total expected costs, which includes total expected fixed costs for opening DCs (first statement), Working inventory cost (second statement), Transportation cost from located DC to the customer (third statement) and Penalty cost of deficiency (fourth statement). Eq. (9) is the second objective function and it is variance of inventory holding, transportation and shortage costs. This is contemplated as absolute magnitude and it is linearized based on the available literature in this field. Eq. (10) is the second objective function and tries to maximize the reliability of located distribution centers. According to Eq. (11), $p$ is the number of distribution centers, which should be located in potentially locations. Eq. (12) states that any customer exactly orders as much as its demand and shortage is not permitted. Eq. (13) emphasizes that, at least, a distribution center should be open to have customer allocation. Eq. (14) is the capacity constraint of distributer. Eq. (15) calculates the annul number of orders in each distribution center. Eq. (16) calculates the total annual demands of $\mathrm{DC}_{\mathrm{j}}$ (due to fluctuations of customer demands, $\geq$ is considered). Eq. (17) is the limitation of supplier's capacity, Eq. (18) shows the amount of goods shipped from each supplier to each distribution center, Eq. (19) is equilibrium constraint in $D C_{j}$ and expresses the difference between incoming goods to $D C_{j}$ and the outputs from it in case of either disruption/shortage or normal situation. Eq. (20) states that the maximum amount of delivered products from the normal distribution center (backup) to the disrupted distribution center can be as much as the amount that suppliers sent them. Eq. (21) shows that each distribution center could order products in maximum as much as its needs (because they may be faced shortage). Eq. (22) states that 
1474

there must be an opened distribution center to be allocated for the suppliers. Eq. (23) states that a distribution center should be open to allow the suppliers send goods to them. Eq. (24) is the constraints resulting from linearization of costs variance. Eq. (25) shows that the reliability of each distributer center is in maximum when there is no disruption in that center. Eqs. (26-32) are limitations of the signs.

\section{Chance Constraint}

Note that constrains given by Eq. (14) and Eq. (16) are probability. When we consider normal distribution for demand and using Probability Constraint, Therefore, Eq. (7) is reformulated as follows,

$$
\begin{aligned}
& \left(\sum_{k} D_{k} Y_{j k} \leq\left(1-a_{j s}\right) \operatorname{cap}_{j} X_{j}\right) \geq 1-\alpha \\
& p\left(\frac{\sum_{k} D_{j} Y_{j k}-\sum_{k} \mu_{k} Y_{j k}}{\sqrt{\sum_{k} \sigma^{2}{ }_{k} Y_{j k}{ }^{2}}} \leq \frac{\left(1-a_{j s}\right) \operatorname{cap}_{j} X_{j}-\sum_{k} \mu_{k} Y_{j k}}{\sqrt{\sum_{k} \sigma^{2}{ }_{k} Y_{j k}{ }^{2}}}\right) \geq 1-\alpha \rightarrow \frac{\left(\left(1-a_{j s}\right) \operatorname{cap}_{j} X_{j}-\sum_{k} \mu_{k} Y_{j k}\right)}{\sqrt{\sum_{k} \sigma^{2}{ }_{k} Y_{j k}{ }^{2}}} \geq Z_{1-\alpha}
\end{aligned}
$$

Eq. (11) can be written as follows,

$$
\begin{aligned}
& \left(D_{j} \geq \sum_{k} D_{k} Y_{j k}\right) \geq 1-\alpha \\
& p\left(\frac{D_{j}-\sum_{k} \mu_{k} Y_{j k}}{\sqrt{\sum_{k} \sigma^{2}{ }_{k} Y_{j k}{ }^{2}}} \geq \frac{\sum_{k} D_{k} Y_{j k}-\sum_{k} \mu_{k} Y_{j k}}{\sqrt{\sum_{k} \sigma^{2}{ }_{k} Y_{j k}{ }^{2}}}\right) \geq 1-\alpha \rightarrow \frac{\left(D_{j}-\sum_{k} \mu_{k} Y_{j k}\right)}{\sqrt{\sum_{k} \sigma^{2}{ }_{k} Y_{j k}{ }^{2}}} \geq Z_{1-\alpha}
\end{aligned}
$$

After applying probability constraint, the model can be rewritten as follows:

$$
\begin{aligned}
& \min Z_{1}=\left[\sum_{j} f_{j} \mathrm{x}_{j}+\left[\sum_{j}\left(s_{j} n_{j}+\sum_{i}\left(g_{i j} n_{j}+k_{i j} Z_{i j}\right)+\sum_{s} q_{s}\left(I_{j}\right) h_{j}\right)+\sum_{s} q_{s}\left(\sum_{j \in J_{s}}\left(\sum_{j} E_{j j s} C_{j j}\right)\right)\right]\right. \\
& \left.+\sum_{j} \sum_{k} d_{j k} \mu_{k} y_{j k}+\sum_{j} \sum_{s} q_{s} b_{j s} \pi_{j}\right] \\
& \min Z_{2}=\sum_{s} q_{s}\left[\sum_{\mathrm{j}} \mathrm{I}_{\mathrm{j}} \mathrm{h}_{\mathrm{j}}+\sum_{\mathrm{j} \in \mathrm{j}_{\mathrm{s}}}\left(\sum_{\mathrm{j}} \mathrm{T}_{\mathrm{j} j \mathrm{~s}} \mathrm{C}_{\mathrm{j} j} \mathrm{X}_{\mathrm{j}}\right)+\sum_{\mathrm{j}} \mathrm{b}_{\mathrm{js}} \mathrm{\pi}_{\mathrm{j}}\right] \\
& +\partial \sum_{s \in S} q_{s}\left[\left(\sum_{\mathrm{j}} \mathrm{I}_{\mathrm{j}} \mathrm{h}_{\mathrm{j}}+\sum_{j \in \mathrm{j}_{\mathrm{s}}}\left(\sum_{\mathrm{j}} \mathrm{T}_{\mathrm{j} j \mathrm{~s}} \mathrm{C}_{\mathrm{jj}} \mathrm{X}_{\mathrm{j}}\right)+\sum_{\mathrm{j}} \mathrm{b}_{\mathrm{js}} \mathrm{\pi}_{\mathrm{j}}\right)\right. \\
& \left.-\sum_{s \in S} q_{s}\left(\sum_{j} \mathrm{I}_{\mathrm{j}} \mathrm{h}_{\mathrm{j}}+\sum_{\mathrm{j} \in \mathrm{j}_{s}}\left(\sum_{\mathrm{j}} \mathrm{T}_{\mathrm{j} j \dot{S}} \mathrm{C}_{\mathrm{j} j} \mathrm{X}_{\mathrm{j}}\right)+\sum_{\mathrm{j}} \mathrm{b}_{\mathrm{j} s} \mathrm{\pi}_{\mathrm{j}}\right)+2 \theta_{S}\right]
\end{aligned}
$$

Subject to:

Eqs. (11)-(13) 
$\frac{\left(\left(1-a_{j s}\right) c a p_{j} X_{j}-\sum_{k} \mu_{k} Y_{j k}\right)}{\sqrt{\sum_{k} \sigma^{2}{ }_{k} Y_{j k}^{2}}} \geq Z_{1-\alpha} \quad \forall s, j$

Eq. (15)

$\frac{\left(D_{j}-\sum_{k} \mu_{k} Y_{j k}\right)}{\sqrt{\sum_{k} \sigma^{2}{ }_{k} Y_{j k}^{2}}} \geq Z_{1-\alpha} \quad \forall j \in J$

Eqs. (17-32)

\section{Solution Approach}

The proposed model is solved using Lingol1 to find some optimal solutions. Since the problem formulation is a multi-objective one, we use epsilon constraint method. Epsilon constraint method is known as one of the public techniques for handling multi-objective problems.

$\min f_{1}(x) \mid x \in X, f_{2}(x) \leq \varepsilon_{2}, \cdots, f_{n}(x) \leq \varepsilon_{n}$

$\varepsilon$-constraint method has the following steps:

1. It selects one of the objective functions as the main function and place the rest of objective functions to constraints.

2. It solves the problem each time by Contemplating one of the objective functions and getting the optimal amounts of each objective function.

3. It divides the optimum interval between the sub-objective functions into pre-defined values and obtaining a values table for $\varepsilon_{2} \ldots \varepsilon_{n}$

\section{Computational result}

To illustrate the applicability of the model, 2 numerical examples have been presented; all data are provided in the appendix. It should be noted that the related calculations were done using Lingo 11 in a personal computer with Intel core 2 and 2 GB RAM. Numerical values are given for each variable. It all costs are to ten thousand Rials. Capacity and demand are to tons (Bozorgi Atoei et al., 2012)

Table 1

Parameter value

\begin{tabular}{|c|c|}
\hline parameter & Value \\
\hline Supplier capacity (capj) & Uniform (750-810) \\
\hline Constant costs for opening and operating DC $(\mathrm{fj})$ & Uniform $(480000-525000)$ \\
\hline Fixed cost per order from (s) & Uniform $(650-750)$ \\
\hline The annual maintenance cost per unit in DC (h) & Uniform (64-78) \\
\hline Capacity of DC (capj) & Uniform $(710-840)$ \\
\hline The penalty cost of shortage in service to DC per unit of demand $\left(\pi_{j}\right)$ & Uniform (100-320) \\
\hline customer demand (Dk) & $\operatorname{normal}(280,24)$ \\
\hline Probability of each scenario (qs) & Uniform $(0-0.5)$ \\
\hline Transportation costs from the DCj to customers (djk) & Uniform (10-19) \\
\hline Transportation costs from the suppliers to the DCj (kij) & Uniform (11-22) \\
\hline Transportation cost unit from each normal to each deficient (cji) & Uniform (41-25) \\
\hline Fixed cost per shipment from supplier to distribution center(gij) & Uniform (100-250) \\
\hline fraction of total capacity of which has been ruined in scenario s (ajs) & Uniform $(0,1)$ \\
\hline Fraction of capacity of supplier i under scenario s which is eliminated due to disruption (ais) & Uniform $(0,1)$ \\
\hline
\end{tabular}

According to $\varepsilon$-constraint method described above, in any time are achieved different amount for objective functions that will be displayed in Table 2. Colorful houses in the table above, the objective function values are considered as the main objective and other objective functions are placed in constraints. As can be seen, in each row the best value (in terms of minimum or maximum) related on the main objective function. $\varepsilon$-constraint method requires the best and worst values that specified in table. 
Table 2

Result of lingo solution

\begin{tabular}{|c|c|c|c|c|c|c|}
\hline Problem \# & sup/DC/cus/sen./p & State & result & & & $\begin{array}{l}\text { best value } \\
\text { nadir } \\
\text { value }\end{array}$ \\
\hline \multirow{3}{*}{1} & \multirow{3}{*}{$1-2-2-2-2$} & \multirow{3}{*}{ global } & Obj1 21504120 & 21619540 & 21677560 & $\begin{array}{l}21504120 \\
21677560\end{array}$ \\
\hline & & & Obj2 116136.9 & 111300 & 138637.3 & $\begin{array}{r}111300 \\
138637.3\end{array}$ \\
\hline & & & Obj30.75 & 0.75 & 3 & $\begin{array}{r}3 \\
0.75 \\
\end{array}$ \\
\hline \multirow{3}{*}{2} & \multirow{3}{*}{$3-4-3-3-3$} & \multirow{3}{*}{ global } & Obj1 22844370 & 28972120 & 30830660 & $\begin{array}{l}22844370 \\
30830660\end{array}$ \\
\hline & & & Obj2346006.8 & 227307.7 & 683907.1 & $\begin{array}{l}227307.7 \\
683907.1\end{array}$ \\
\hline & & & Obj3 0.0025 & 0.004371 & 4 & $\begin{array}{r}4 \\
0.0025\end{array}$ \\
\hline
\end{tabular}

We consider the first objective function as the main objective function and divide the other objectives' ranges by 5 intervals for the rest of objective functions. Figure 1 shows the direction of objective functions for problem 1.

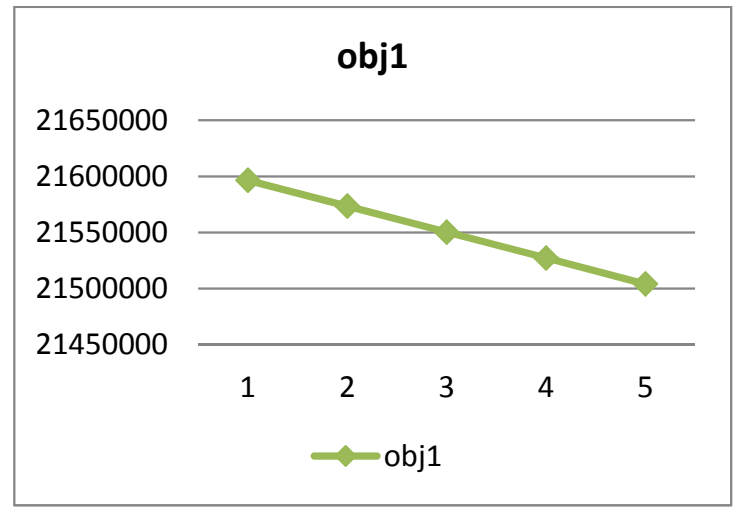

a. expected value cost

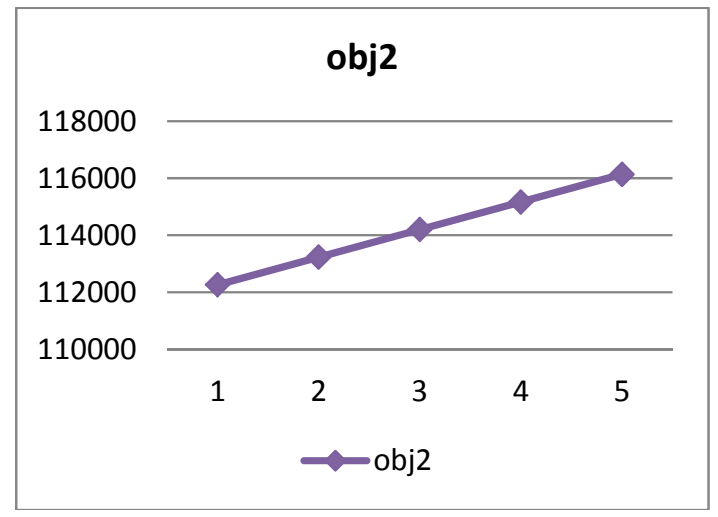

b. variance

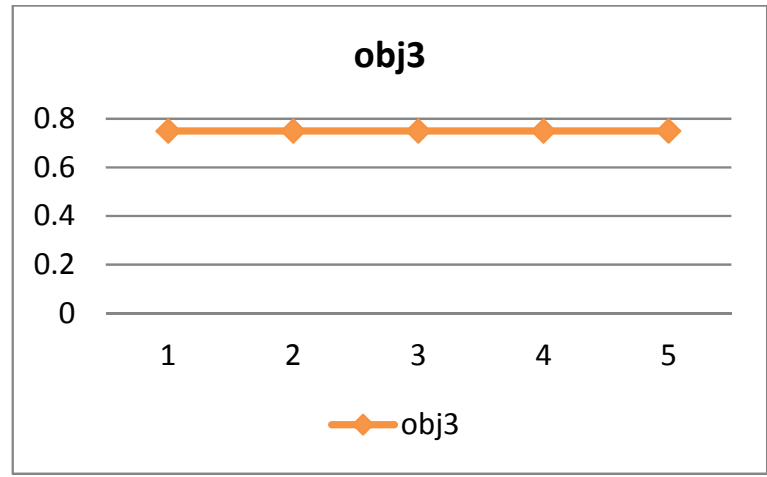

c. reliability

Fig1. Test problem 1

According to the figure, the first and second objective function are opposite directions, which is reasonable and also the first and third objective function are opposite directions, that is acceptable because the first objective function is a minimization and the second objective function is a maximization. 


\section{Conclusion}

We have presented a multi-objective reliable capacitated supply chain network design (RSCND) model by considering random disruption risks in accordance with the real-word. The proposed model determines the optimal location of distribution centers (DC) with the highest reliability, the best plan to assign customers to opened DCs, assigns opened DCs to suitable suppliers with lowest transportation cost and variance of holding, transportation and shortage costs. Random disruption occurs at the location, capacity of the distribution centers (DCs) and suppliers. We have assumed that a disrupted DC and a disrupted supplier may lose a portion of their capacities, and the rest of the disrupted DC's demand can be supplied by other DCs. In addition, we considered shortage in DCs, which can occur in either normal or disruption conditions and DCs, can support each other in such circumstances. Unlike other studies in the extent of literature, we have used new approach to model the reliability of DCs; we consider reliability as a range .In order to solve the proposed model lingo software is applied.

\section{- $\quad$ Future research}

For future research, we suggest five directions as follows:

$\checkmark$ Contemplating metaheuristics solution methods to solve the model, such as NSGA-II, MODA , MOPSO and so on.

$\checkmark$ Taking in to account correlated distribution probabilities for the model.

$\checkmark$ Considering other cost factors such as reconstruction cost of ruined facilities or destroyed inventory, etc.

\section{References}

Aryanezhad, M.B, \& Jabbarzadeh, A. ( 2009). An integrated model for location-inventory problem with random disruptions. Proceedings of the International Conference on Computers \& Industrial Engineering, 39, 687-703.

Azad, N., \& Davoudpour, H. (2011). Stochastic distribution network design with reliability, consideration Journal of Zhejiang University-SCIENCE C (Computers \& Electronics). in press, doi: $10.1631 /$ jzus.C11a0087.

Azad, N., Saharidis, G. K.D., Davoudpour, H., Malekly, H. \& Yektamaram, S.A. (2012) Strategies for protecting supply chain networks against facility and transportation disruptions: an improved Benders decomposition approach. Springer Science Business Media, Annual Operation research, DOI 10.1007/s10479-012-1146-x.

Azaron, A., Brown, K. N., Tarim, S.A., \& Modarres, M. (2008). A multi-objective stochastic programming approach for supply chain design considering risk. International Journal of Production Economics, 116, 129-138.

Bérubé, J. F., Gendreau, M. \& Potvin, J.Y. (2009). An exact $\varepsilon$-constraint method for bi-objective combinatorial optimization problems: Application to the traveling salesman problem with profits. European Journal of Operational Research, 194, 39-50.

Berman, O., Krass, D., \& Menezes, M. B. C. (2007). Facility reliability issues in network p-median problems: Strategic centralization and co-location effects. Operations Research, 55 (2), 332-350.

Berman, O., Krass, D., \& Meneze, M. B. C. (2009). Location facilities in the presence of disruptions and information. Decision Science, 40, 845-868.

Bozorgi Atoei, F., Teimory, E., Bozorgi-Amiri, A. (2013). Designing reliable supply chain network with disruption risk. International Journal of Industrial Engineering Computations. 4(1).

Bozorgi Amiri, A., Cui, T., Ouyang, Y. \& Shen, Z.J.M. (2010). Reliable facility location design under the risk of disruptions. Operations Research, 58 (4), 998-1011.

Daskin, M. S. \& Coullard, C. R. (2002). An inventory-location model: Formulation, solution algorithm and computational results. Annals of Operations Research, 110, 83-106. 
Drezner, Z. (1987). Heuristic solution methods for two location problems with unreliable facilities. Journal of the Operational Research Society, 38, (6), 509-514.

Gharegozloo, S., Jabalameli, M.S., \& Bozorgi-Amiri, A. (2013). A location-inventory model for distribution centers in a three-level supply chain under uncertainty. International Journal of Industrial Engineering Computations, 4(1).

Lee, S. D. (2001). On solving unreliable planar location problems. Computers and Operations Research, 28(4), 329-344.

Li, X., \& Ouyang, Y. (2010). A continuum approximation approach to reliable facility location design under correlated probabilistic disruptions. Transportation Research Part B: Methodological, 44(4), 535-548.

Lim, M., Daskin, M. S., Bassamboo, A., \& Chopra, S. (2010). A Facility Reliability Problem: Formulation, Properties, and Algorithm. Naval Research Logistics, 57(1), 58-70

Miranda, P. A. \& R. A. Garrido (2004). Incorporating inventory control decisions into a strategic distribution network design model with stochastic demand. Transportation Research Part E, 40, 183-207.

Ozsen, L. \& C. R. Coullard. (2008). Capacitated warehouse location model with risk pooling. Naval Research Logistics, 55(4), 295-312.

Park, S., Lee, T. \& Sung, C.S. (2010). A three-level supply chain network design model with riskpooling and lead times. Transportation Research Part E, 46, 563-581.

Peng P., Snyder , L., Lim, \& Liu. (2011). Reliable logistics networks design with facility disruptions. Transportation Research, 45(8), 1190-1211.

Qi, L., Shen, Z.-J., \& Snyder, L. V. (2010). The effect of supply disruptions on supply chain design decisions. Transportation Science, 44(2), 274-289.

Shen, Z.J.M., Coullard, C. \& Daskin, M.S. (2003). A joint location-inventory model. Transportation Science, 37, 40-55.

Shu, J. \& Teo, C. (2005). Stochastic transportation inventory network design problem. Operational Research, 53(1), 48-60.

Snyder, L.V. (2003). Supply chain robustness and reliability: Models and algorithms. Ph.D. dissertation, Northwestern University, Department of Industrial Engineering \& Management Sciences, Evanston, IL.

Snyder, L. V., \& Daskin, M. S. (2005). Reliability models for facility location: The expected failure cost case. Transportation Science, 39 (3), 400-416.

Snyder, L. V., Scaparra, P. M., Daskin, M. S., \& Church R.L. (2006). Planning for disruptions in supply chain networks. In Tutorials in Operations Research, INFORMS, 234-257.

Snyder, L. V., Daskin, M. S. \& Teo, C. (2007). The stochastic location model with risk pooling. European Journal of Operational Research, 179(3), 1221-1238.

Snyder, L. V., Atan, Z., Peng, P., Rong, Y., Schmitt, A. \& Sinsoysal, B. (2010). OR/MS models for supply chain disruptions: A review. Social Science Research Network, Working papers series.

Zegordi, S.H., \& Davarzani, H. (2012). Developing a supply chain disruption analysis model: application of colored Petri-nets. Expert Systems with Applications, 39, (2), 2102-2111 